PAPER

\title{
Outcomes following childhood head injury: a population study
}

\author{
C A Hawley, A B Ward, A R Magnay, J Long
}

J Neurol Neurosurg Psychiatry 2004;75:737-742. doi: 10.1136/jnnp.2003.020651

See end of article for authors' affiliations

....................

Correspondence to: Dr C Hawley, Principal Research Fellow, Centre for Health Services Studies, University of Warwick, Coventry CV4 7AL, UK; c.a.hawley@warwick. ac.uk

Received 13 June 2003

In revised form

19 September 2003

Accepted 6 October 2003
Objectives: To identify outcomes following head injury (HI) among a population of children admitted to one hospital centre and to compare outcomes between different severity groups.

Methods: A postal follow up of children admitted with $\mathrm{HI}$ to one National Health Service Trust, between 1992 and 1998, was carried out. Children were aged 5-15 years at injury (mean 9.8), followed up at a mean of 2.2 years post-injury. Parents of 526 injured children ( 419 mild, 58 moderate, 49 severe) and 45 controls completed questionnaires. Outcomes were assessed using the King's Outcome Scale for Childhood Head Injury (KOSCHI).

Results: Frequent behavioural, emotional, memory, and attention problems were reported by one third of the severe group, one quarter of the moderate, and 10-18\% of the mild. Personality change since HI was reported for 148 children (28\%; $21 \%$ mild HI, $46 \%$ moderate, $69 \%$ severe). There was a significant relationship between injury severity and $\mathrm{KOSCHI}$ outcomes. Following the $\mathrm{HI}, 252$ (48\%) had moderate disability (43\% mild HI, 64\% moderate, 69\% severe), while $270(51 \%)$ made a good recovery $157 \%$ mild $\mathrm{HI}, 36 \%$ moderate, $22 \%$ severe). There was a significant association between social deprivation and poor outcome $(p=0.002)$. Only $30 \%$ (158) of children received hospital follow up after the HI. All children with severe disability received appropriate follow up, but $64 \%$ of children with moderate disability received none. No evidence was found to suggest a threshold of injury severity below which the risk of late sequelae could be safely discounted.

Conclusions: Children admitted with mild $\mathrm{HI}$ may be at risk of poor outcomes, but often do not receive routine hospital follow up. A postal questionnaire combined with the $\mathrm{KOSCHI}$ to assess outcomes after $\mathrm{HI}$ may be used to identify children who would benefit from clinical assessment. Further research is needed to identify factors that place children with mild $\mathrm{HI}$ at risk of late morbidity.
$\mathrm{H}$ ead injury (HI) is a leading cause of mortality or permanent disability in children and adolescents. ${ }^{1-3}$ In the UK, it has been estimated that each year, approximately 3000 children acquire significant new neurological or cognitive disability as a result of HI. ${ }^{4}$ Head injury has been the subject of a recent UK Government Enquiry, ${ }^{5}$ which called for research on the incidence of $\mathrm{HI}$ and subsequent disability, to help inform planning for community based health care.

For children, a head injury can lead to persistent cognitive and neurobehavioural deficits, intellectual, academic, and personality adjustment problems, ${ }^{6-10}$ and family stress. ${ }^{11-13}$ Children with head injuries may present with a variety of prolonged difficulties and problems, all of which may interact in a complex manner. ${ }^{14}$ Even mild HI may lead to persistent cognitive and behavioural deficits. ${ }^{15-17}$

The measurement of outcomes following childhood head injury has been hampered by the absence of simple but reliable measures and this has hindered direct comparisons between different studies. For adults, the Glasgow Outcome Scale $(\mathrm{GOS})^{18}$ is widely used, but until recently, there has been no equivalent scale for children. A new scale, the King's Outcome Scale for Childhood Head Injury (KOSCHI), has been developed to measure outcomes following HI in children, based on the GOS, but with extra sensitivity at the milder end of the disability range. ${ }^{19}$

The current study was designed to carry out a postal follow up of all children admitted with a head injury to a single hospital centre serving one health region. The aim was to compare outcomes between different severity groups using the KOSCHI.

\section{METHODS}

\section{Subjects}

The population forming the study group was identified by using a comprehensive Head Injury Register of all children admitted to North Staffordshire Hospital NHS Trust with a head injury. The Register is maintained by a dedicated head injury nurse and linked to the Trauma Centre. Patients were identified retrospectively from November 1992-December 1997, and prospectively from January-December 1998. During this period, there were 986 children on the register. Of these $12(1.2 \%)$ died as a result of the HI. In 1998, a postal questionnaire was sent to the parents of all 974 surviving children aged 5-15 years at injury. All children had been discharged from acute hospital care. Questionnaires were completed by 526 parents. The children of 523 respondents were living in the community at the time of the survey.

For all surviving children, injury severity was determined by Glasgow Coma Scale (GCS ${ }^{20}$ scores and/or duration of loss of consciousness, using the classification of mild, moderate, or severe head injury defined by the British Society of Rehabilitation Medicine (table 1). ${ }^{21}$ In North Staffordshire, GCS is reliably recorded as it is used routinely in a major longitudinal study on trauma.

A control group was identified by interviewing a sub-group of 97 questionnaire respondents (49 mild HI, 19 moderate, and 29 severe). The family was asked to give details of a child without history of head injury, and of the same age and sex as the injured child to act as a control. Forty five control

Abbreviations: GOS, Glasgow Outcome Scale; HI, head injury; KOSCHI, King's Outcome Scale for Childhood Head Injury; SEN, special educational needs 


\section{Table 1 Definitions of injury severity}

\begin{tabular}{ll}
\hline $\begin{array}{l}\text { Severity of } \\
\text { traumatic } \\
\text { brain injury }\end{array}$ & Definition \\
\hline Mild & $\begin{array}{l}\text { An injury causing unconsciousness for less than } \\
15 \text { minutes and a GCS after initial resuscitation of 13-15 }\end{array}$ \\
Moderate & $\begin{array}{l}\text { An injury causing unconsciousness for more than } \\
15 \text { minutes and a GCS after initial resuscitation of 9-12 }\end{array}$ \\
Severe & $\begin{array}{l}\text { An injury causing unconsciousness for more than } 6 \text { hours } \\
\text { and a GCS after initial resuscitation of 3-8 }\end{array}$ \\
&
\end{tabular}

children participated in the study; none had a history of head injury or any neurological abnormality. Parents of control children completed the same checklist of current symptoms as parents of the HI group.

\section{Questionnaire content}

A list of symptoms was devised using commonly reported problems identified from the literature and the King's HI outpatient follow-up checklist. ${ }^{19}$ The questionnaire explored changes in the child post-HI, and covered mobility, behaviour, personality, mood, depression, anxiety, memory, attention, communication, comprehension, sleep pattern, nightmares, headaches, sensory difficulties, epilepsy, other injuries (for example, orthopaedic), return to school, learning difficulties, special educational needs status, and school related problems.

Questionnaires were sent to parents/guardians together with a letter explaining the study and inviting them to discuss issues raised by the survey with a head injury nurse. Four weeks later, non-responders were sent a second letter and another copy of the questionnaire. Four weeks after this, non-responders were telephoned by the head injury nurse inviting them to participate.

\section{Measurement of outcome}

Outcomes were calculated using KOSCHI scores derived from questionnaire responses. All questionnaires were scored, without knowledge of injury severity, by one team member $(\mathrm{CH})$, who is experienced in using the KOSCHI and was a participant in the KOSCHI inter-rater reliability exercise. ${ }^{19}$ The KOSCHI (table 2) contains five main categories: $1=$ death, 2 = vegetative, $3=$ severe disability, $4=$ moderate disability, and $5=$ good recovery. Categories 3, 4, and 5 are sub-divided into $(a)$ more deficits and $(b)$ fewer deficits.

The Townsend Deprivation Index was used to measure social deprivation, using postcodes. ${ }^{22}$ The higher the positive score the more deprived an area and the higher the negative score the more prosperous. For the UK, the average score is 0 , for North Staffordshire the average score is -0.49 .

Statistical analyses were carried out using SPSS Version 9.0. Categorical data were analysed using $\chi^{2}$ tests; the $\chi^{2}$ test for trend was used to determine whether there was a linear trend across severity groups. Normally distributed continuous data was analysed using Student's $t$ test.

\section{RESULTS}

Forty eight envelopes were returned as undeliverable (addressee untraceable). Of the 926 presumed valid addresses, completed questionnaires were returned by 526 families, an overall response rate of $56.8 \%$, averaged over 6 years of recruitment between 1992 and 1998. Response rates for different severity groups were: mild 55.6\% (419 returned/753 sent); moderate $57.4 \%$ (58 returned/101 sent); severe $68.1 \%$ (49 returned/72 sent). Within 2 years of injury the overall response rate was $62.8 \%$ (218 returned/347 sent),

\section{Table $2 \mathrm{KOSCHI}$ category definitions}

\begin{tabular}{|c|c|}
\hline Category & Definition \\
\hline 1 Death & \\
\hline 2 Vegetative & $\begin{array}{l}\text { Breathes spontaneously. No evidence of verbal } \\
\text { or non-verbal communication or response to } \\
\text { commands. }\end{array}$ \\
\hline 3 Severe disability A & $\begin{array}{l}\text { Conscious, totally dependent. May be able to } \\
\text { communicate. Requires specialised } \\
\text { educational/rehabilitation setting. }\end{array}$ \\
\hline Severe disability B & $\begin{array}{l}\text { Limited self care abilities and predominantly } \\
\text { dependent. May have meaningful } \\
\text { communication. Requires specialised } \\
\text { educational/rehabilitation setting. }\end{array}$ \\
\hline $\begin{array}{l}4 \text { Moderate disability } \\
\text { A }\end{array}$ & $\begin{array}{l}\text { Mostly independent for daily living, but needs a } \\
\text { degree of supervision/help for physical or } \\
\text { behavioural problems. Has overt problems. } \\
\text { May be in specialised rehabilitation/ } \\
\text { educational setting or in mainstream school } \\
\text { requiring special needs assistance. Behavioural } \\
\text { problems may have caused patient to be } \\
\text { disciplined or excluded from school. }\end{array}$ \\
\hline $\begin{array}{l}\text { Moderate disability } \\
\text { B }\end{array}$ & $\begin{array}{l}\text { Age appropriately independent for daily living, } \\
\text { but with neurological sequelae frequently } \\
\text { affecting daily life, including behavioural and } \\
\text { learning difficulties. May also have frequent } \\
\text { headaches. Likely to be in mainstream school } \\
\text { with or without special needs assistance. }\end{array}$ \\
\hline 5 Good recovery A & $\begin{array}{l}\text { Appears to have made a full functional } \\
\text { recovery, but has residual pathology } \\
\text { attributable to head injury. May suffer } \\
\text { headaches that do not affect school or social life, } \\
\text { and may occasionally have some of the } \\
\text { problems listed on the head injury checklist. }\end{array}$ \\
\hline Good recovery B & $\begin{array}{l}\text { The information available implies that child has } \\
\text { made a complete recovery. No sequelae } \\
\text { identified. }\end{array}$ \\
\hline
\end{tabular}

representing $173(62.8 \%)$ mild, $23(62.2 \%)$ moderate, and 22 $(68.8 \%)$ severe.

In order to ensure that responders were representative of all children admitted to North Staffordshire NHS Trust with $\mathrm{HI}$, patient characteristics of questionnaire responders were compared with those of non-responders. There were no statistically significant differences between groups. Responders were virtually identical to non-responders for sex (male: responders 70\%, non-responders 67\%), injury severity (responders: $80 \%$ mild, 11\% moderate, 9\% severe; non-responders: $83 \%$ mild, $11 \%$ moderate, $6 \%$ severe), age at injury (mean of 9.8 years, both groups), ethnicity (97\% white, both groups), time since injury (mean no. of years post-injury: responders 2.1, non-responders 2.5) and social deprivation (Townsend means: responders: +1.0, nonresponders: +1.4$)$.

\section{Participants}

Participants were 526 children with HI, aged 5-15 years at injury. The most common causes of HI were falls (213, $40.5 \%)$ and road traffic accidents $(144,27.4 \%)$, especially as pedestrians $(92,17.5 \%)$. At follow up, children ranged from $\leqslant 1$ year post-injury $(106,20.2 \%)$ to 6 years post-injury $(57$, $10.8 \%$ ), with a mean (SD) of 2.2 (1.7) years. Characteristics of participants are shown in table 3.

The mean (SD) Townsend deprivation score for families in the HI group was +0.69 (2.9), compared with the mean score $(-0.49)$ for the general population of North Staffordshire using the one sample $t$ test. The difference was significant $(\mathrm{p}=0.001, t=9.08,95 \%$ confidence interval (CI) 0.92 to 1.44). The majority of families lived in areas with positive scores $(60.6 \%) ; 62$ families (10.9\%) lived in considerably deprived areas (scores of $\geqslant+3.55$ ), whereas 95 families (19.2\%) lived in the most affluent areas (scores of $\leqslant-2.4$ ). In the control group, the mean (SD) Townsend deprivation 


\begin{tabular}{|c|c|c|c|c|}
\hline Variable & $\begin{array}{l}\text { Mild HI } \\
n=419\end{array}$ & $\begin{array}{l}\text { Moderate HI } \\
\mathrm{n}=58\end{array}$ & $\begin{array}{l}\text { Severe HI } \\
n=49\end{array}$ & $\begin{array}{l}\text { Control } \\
n=45\end{array}$ \\
\hline Gender: no. male (\%) & $292(69.7)$ & $47(81)$ & $29(59.2)$ & $27(60)$ \\
\hline Age at injury (years) & & & & NA \\
\hline Mean & 9.6 & 10.12 & 11.24 & \\
\hline Median & 9.0 & 11.0 & 11.0 & \\
\hline SD & 3.08 & 3.0 & 3.16 & \\
\hline Range & $5-15$ & $5-15$ & $5-15$ & \\
\hline \multicolumn{5}{|c|}{ Age at time of follow-up (years) } \\
\hline Mean & 12.31 & 12.81 & 13.76 & 11.91 \\
\hline Median & 12.0 & 13.0 & 13.0 & 12.0 \\
\hline SD & 3.52 & 3.46 & 3.52 & 2.89 \\
\hline Range & $5-21$ & $7-21$ & $7-21$ & $5-17$ \\
\hline \multicolumn{4}{|c|}{ Years between injury and follow-up } & NA \\
\hline Mean & 2.23 & 2.29 & 1.86 & \\
\hline Median & 2.0 & 2.0 & 2.0 & \\
\hline SD & 1.64 & 1.77 & 1.51 & \\
\hline Range & $0-5$ & $0-5$ & $0-5$ & \\
\hline Ethnicity: no. white (\%) & 397 (94.7\%) & $58(100 \%)$ & $47(95.9 \%)$ & $44(97.8 \%)$ \\
\hline Mechanism of injury & & & & NA \\
\hline Fall (\%) & $193(46.1 \%)$ & $16(27.6 \%)$ & $4(8.2 \%)$ & \\
\hline RTA pedestrian (\%) & $48(11.5 \%)$ & $15(25.9 \%)$ & $29(59.2 \%)$ & \\
\hline RTA in vehicle (\%) & $8(1.9 \%)$ & $4(6.9 \%)$ & $8(16.3 \%)$ & \\
\hline RTA cyclist (\%) & $22(5.3 \%)$ & $4(6.9 \%)$ & $6(12.2 \%)$ & \\
\hline Fall from bicycle (\%) & $44(10.5 \%)$ & $3(5.2 \%)$ & 0 & \\
\hline Assault (\%) & $20(4.8 \%)$ & $4(6.9 \%)$ & 0 & \\
\hline Hit by object & 60 (14.3\%) & $3(5.2 \%)$ & $1(2 . \%)$ & \\
\hline Sport & $17(4.1 \%)$ & $5(8.6 \%)$ & 0 & \\
\hline Other & $7(1.7 \%)$ & $4(6.9 \%)$ & $1(2 \%)$ & \\
\hline Total & $419(100 \%)$ & $58(100 \%)$ & $49(100 \%)$ & \\
\hline
\end{tabular}

score was $-0.103(2.6)$. Townsend scores were compared for the control and HI groups using the independent samples $t$ test; there was no significant difference between groups $(\mathrm{p}=0.114, t=1.58,95 \% \mathrm{CI}:-0.19$ to 1.76$)$.

\section{Other injuries}

Along with the HI, 209 (39.8\%) had suffered other injuries at the time, such as fractures, chest, or facial injuries. Other injuries were suffered by 145 children (34.6\%) with mild, 28 (49.1\%) with moderate, and 36 (73.5\%) with severe HI. There was a significant linear trend across severity groups $\left(\mathrm{p}=0.0001, \chi^{2}=35.16, \mathrm{df}=1\right)$. At follow up, other injuries were still affecting $62(14.8 \%)$ of the mild, $16(28.1 \%)$ of the moderate, and $15(30.6 \%)$ of the severe groups. There was a significant linear trend across severity groups $(p=0.0001$, $\left.\chi^{2}=14.3, \mathrm{df}=1\right)$. Overall, 10 children $(1.9 \%)$ suffered from epilepsy, which was a new problem since the HI for 8 of them ( 5 mild ( $1.2 \%)$, 1 moderate ( $1.8 \%), 2$ severe $(4.1 \%)$ ). There were no significant differences between groups. The incidence of epilepsy amongst children in the UK as a whole is $0.7-0.8 \%{ }^{23}$

\section{Hospital follow up post-injury}

After hospital discharge, 30\% (158) of the study group were followed up by the admitting hospital. In the mild group, 91 children $(21.7 \%)$ were followed up; however many of these appointments were due to accompanying other injuries. Half of the moderate group $(29,50.9 \%)$, and 38 of the severe group $(77.6 \%)$ had a follow up appointment. There was a significant linear trend across severity groups $\left(p=0.0001, \chi^{2}=71.37\right.$, $\mathrm{df}=1$ ).

Only 40 children $(7.6 \%)$ received any form of therapy following their head injury: 14 mild $(3.3 \%), 8$ moderate ( $14 \%)$, and 14 severe (36.7\%). There was a significant linear trend across severity groups $\left(\mathrm{p}=0.0001, \chi^{2}=71.25, \mathrm{df}=1\right)$. Questionnaire respondents were invited to discuss issues raised by the questionnaire with a head injury nurse. One third of parents $(182,34.6 \%)$ accepted this offer: $131(31.2 \%)$ in the mild, $23(40.4 \%)$ in the moderate, and $28(57.1 \%)$ in the severe group. There was a significant linear trend across severity groups $\left(p=0.0001, \chi^{2}=13.69, d f=1\right)$.

Return to school and identification of special needs

Most children $(475,90.6 \%)$ returned to the same school after the injury, those who did not were 40 mild $(9.5 \%), 2$ moderate $(3.4 \%)$ and 8 severe $(16.3 \%)$. For the mild group, the most usual reason for not returning to the same school was moving from junior to high school rather than because of the injury. At the time of the survey, current schoolteachers knew of the child's head injury in only 209 cases $(39.8 \%)$, (140 (33.4\%) mild, $32(55.2 \%)$ moderate, and 37 (77.1\%) severe). There was a significant linear trend across severity groups $\left(p=0.0001, \chi^{2}=40.62, d f=1\right)$.

Following the HI, special educational needs (SEN) were identified for 40 children (7.6\%): 23 mild (5.5\%), 2 moderate $(3.4 \%)$, and 15 severe $(31.3 \%)$. There was a significant linear trend across severity groups $\left(\mathrm{p}=0.0001, \chi^{2}=28.44, \mathrm{df}=1\right)$. However, according to parents, SEN help was actually provided for only 26 children (65\%): 15 mild (3.6\%), 2 moderate $(3.4 \%)$ and 9 severe $(18.8 \%)$, also showing a significant linear trend across groups $\left(p=0.0001, \chi^{2}=19.0\right.$, $\mathrm{df}=1$ )

At follow up, 98 children (18.7\%) were currently having difficulties with schoolwork and there was a significant linear trend across severity groups: 65 mild (15.5\%), 16 moderate $(27.6 \%)$, and 17 severe $(35.4 \%) \quad(p=0.0001$, $\left.\chi^{2}=14.5, \mathrm{df}=1\right)$. Since the HI, 96 children $(18.3 \%)$ had been disciplined by the school for problem behaviour (71 mild $(16.9 \%), 14$ moderate $(24.1 \%), 11$ severe $(22.9 \%)) ; 27$ $(5.1 \%)$ had been excluded from school (21 mild (5\%), 3 moderate $(5.2 \%), 3$ severe $(6.3 \%))$. There were no significant differences between groups.

\section{Current symptoms}

Parents of 148 children (28.1\%) believed that the personality of their child had changed since the HI. Of these, $88(20.9 \%)$ had mild, 26 (46.4\%) moderate, and 34 (69.4\%) severe HI. 
Table 4 Current symptoms frequently experienced by the child, as reported by parents

\begin{tabular}{|c|c|c|c|c|c|}
\hline Current symptom & Mild HI & Moderate HI & Severe HI & Control & $\begin{array}{l}\text { Significance } \\
(\mathrm{df}=1)\end{array}$ \\
\hline Headaches $(n=565)$ & $65(15.6 \%)$ & $9(16.4 \%)$ & $13(27.7 \%)$ & $2(4.4 \%)$ & $p=0.002$ \\
\hline Dizziness $(n=559)$ & $12(2.9 \%)$ & $2(7.5 \%)$ & $3(6.4 \%)$ & 0 & $p=0.009$ \\
\hline Temper outbursts $(n=560$ ) & $54(13 \%)$ & $17(31.5 \%)$ & $16(34 \%)$ & 0 & $p=0.0001$ \\
\hline Mood swings $(n=563)$ & $76(18.2 \%)$ & $17(31.5 \%)$ & $17(36.2 \%)$ & $1(2.2 \%)$ & $p=0.0001$ \\
\hline Anxiety $(n=559)$ & $25(6.1 \%)$ & $13(23.6 \%)$ & $12(26.1 \%)$ & $1(2.2 \%)$ & $p=0.0001$ \\
\hline Nightmares $(n=557)$ & $15(3.6 \%)$ & $4(7.7 \%)$ & $3(6.4 \%)$ & $1(2.2 \%)$ & $p=0.218$ \\
\hline $\begin{array}{l}\text { Aggressive behaviour } \\
(n=562)\end{array}$ & $38(9.2 \%)$ & $13(23.6 \%)$ & $12(25.5 \%)$ & 0 & $p=0.0001$ \\
\hline $\begin{array}{l}\text { Feels down or depressed } \\
(n=561)\end{array}$ & $25(6 \%)$ & $10(18.5 \%)$ & 9 (19.1\%) & 0 & $p=0.0001$ \\
\hline Clumsiness $(n=563)$ & $25(6 \%)$ & $7(13 \%)$ & $9(19.1 \%)$ & 0 & $p=0.0001$ \\
\hline Tiredness $(n=565)$ & 48 (11.5\%) & $9(16.1 \%)$ & $16(34 \%)$ & $1(2.2 \%)$ & $p=0.0001$ \\
\hline $\begin{array}{l}\text { Balance and co-ordination } \\
(\mathrm{n}=562)\end{array}$ & $9(2.2 \%)$ & $3(5.5 \%)$ & 10 (20.8\%) & 0 & $p=0.0001$ \\
\hline $\begin{array}{l}\text { Receptive language } \\
(\mathrm{n}=565)\end{array}$ & $23(5.5 \%)$ & $8(14.5 \%)$ & $7(14.6 \%)$ & $1(2.2 \%)$ & $p=0.0001$ \\
\hline $\begin{array}{l}\text { Word finding difficulties } \\
(n=562)\end{array}$ & $15(3.6 \%)$ & 7 (13\%) & $6(12.8 \%)$ & 0 & $p=0.0001$ \\
\hline $\begin{array}{l}\text { Expressive language } \\
(\mathrm{n}=564)\end{array}$ & $14(3.4 \%)$ & $7(12.7 \%)$ & $8(16.7 \%)$ & 0 & $p=0.0001$ \\
\hline Attention $(n=566)$ & $59(14.1 \%)$ & $14(25 \%)$ & $14(29.2 \%)$ & $1(2.2 \%)$ & $p=0.0001$ \\
\hline $\begin{array}{l}\text { Memory for what has been } \\
\text { told }(\mathrm{n}=564)\end{array}$ & $39(9.4 \%)$ & 13 (23.2\%) & 15 (31.9\%) & $1(2.2 \%)$ & $p=0.0001$ \\
\hline $\begin{array}{l}\text { Inappropriate behaviours } \\
(\mathrm{n}=561)\end{array}$ & $22(5.3 \%)$ & 7 (13\%) & $10(21.7 \%)$ & 0 & $p=0.0001$ \\
\hline
\end{tabular}

There was a significant linear trend across severity groups $\left(p=0.0001, \chi^{2}=61.25, \mathrm{df}=1\right)$.

The questionnaire contained a list of symptoms and problems associated with head injury. Parents were asked if, during the past few weeks, their child had experienced any of the symptoms "not at all", "occasionally", or "frequently". Children with mild, moderate, and severe HI and control children were compared using the $\chi^{2}$ test for trend (table 4). There was a significant trend across severity groups for all symptoms except nightmares. Children in the moderate and severe groups experienced most symptoms significantly more frequently than those in the mild group. Only two control children experienced any symptoms frequently.

Current reported symptoms were compared for children $\leqslant 1$ year post-injury and $>1$ year post-injury at follow up. There were few significant differences in the frequency of reporting. Recently injured children in the mild group experienced more nightmares $(p=0.008)$, while the moderate group experienced more nightmares and tiredness $(\mathrm{p}=0.005)$. In the severe group, a higher proportion of those $\leqslant 1$ year post-injury experienced all symptoms more frequently, but significant differences were found for only headaches (recent injuries $54.5 \%$, less recent injuries $18.9 \%$; $\mathrm{p}=0.05$ ) and clumsiness (recent injuries $45.5 \%$, less recent injuries $10.8 \% ; \mathrm{p}=0.02$ ).

\section{KOSCHI outcomes}

KOSCHI outcome scores for all children in the mild, moderate, and severe HI groups are shown by main category and sub-category in table 5 . Four children with severe HI $(8.2 \%)$ had severe disability at follow up. Overall, 252 children $(47.9 \%)$ had moderate disability following the HI, of these $181(43.2 \%)$ had a mild HI. Greater injury severity was associated with worse outcomes $\left(p=0.0001, \chi^{2}=61.64\right.$, $\mathrm{df}=4)$. There was also a significant trend across severity groups $\left(p=0.0001, \chi^{2}=37.66, d f=1\right)$. When compared over the six sub-categories, most children in the mild group scored $4 \mathrm{~B}$ or $5 \mathrm{~A}$, most of the moderate group scored between $4 \mathrm{~A}$ and $5 \mathrm{~A}$, and most of the severe group scored $4 \mathrm{~A}$ or $4 \mathrm{~B}(\mathrm{p}=0.0001$, $\chi^{2}=87.22, \mathrm{df}=10$ ).

Outcomes for children followed up within 1 year of injury were also analysed (table 5). There were significant differences between severity groups for the three main categories $\left(p=0.0001, \quad \chi^{2}=26.71, \quad d f=4\right)$ and six sub-categories

Table $5 \mathrm{KOSCHI}$ scores by injury severity and time since injury

\begin{tabular}{|c|c|c|c|c|c|c|}
\hline $\begin{array}{l}\text { KOSCHI } \\
\text { score }\end{array}$ & $\begin{array}{l}\text { All mild HI } \\
(n=419)\end{array}$ & $\begin{array}{l}\text { All } \\
\text { moderate HI } \\
(n=58)\end{array}$ & $\begin{array}{l}\text { All } \\
\text { severe HI } \\
(n=49)\end{array}$ & $\begin{array}{l}\text { Mild } \mathrm{HI} \\
\leqslant 1 \text { year post- } \\
\mathrm{HI}(\mathrm{n}=79)\end{array}$ & $\begin{array}{l}\text { Moderate } \mathrm{HI} \\
\leqslant 1 \text { year post- } \\
\mathrm{HI}(\mathrm{n}=15)\end{array}$ & $\begin{array}{l}\text { Severe } \mathrm{HI} \\
\leqslant 1 \text { year post- } \\
\mathrm{HI}(\mathrm{n}=12)\end{array}$ \\
\hline $\begin{array}{l}3 \text { Severe } \\
\text { disability }\end{array}$ & 0 & 0 & $4(8.2 \%)$ & 0 & 0 & $2(16.7 \%)$ \\
\hline $3 \mathrm{~A}$ & 0 & 0 & $1(2.0 \%)$ & 0 & 0 & $1(8.3 \%)$ \\
\hline $3 B$ & 0 & 0 & $3(6.1 \%)$ & 0 & 0 & 1 (8.3\%) \\
\hline $\begin{array}{l}4 \text { Moderate } \\
\text { disability }\end{array}$ & 181 (43.2\%) & $37(63.8 \%)$ & $34(69.4 \%)$ & $33(41.8 \%)$ & 12 (80\%) & $8(66.7 \%)$ \\
\hline $4 \mathrm{~A}$ & $34(8.1 \%)$ & $15(25.9 \%)$ & $17(34.7 \%)$ & $10(12.7 \%)$ & $5(33.3 \%)$ & $5(41.7 \%)$ \\
\hline $4 \mathrm{~B}$ & $147(35.1 \%)$ & 22 (37.9\%) & 17 (34.7\%) & 23 (29.1\%) & 7 (46.7\%) & $3(25 \%)$ \\
\hline $\begin{array}{l}5 \text { Good } \\
\text { recovery }\end{array}$ & $238(56.8 \%)$ & $21(36.2 \%)$ & 11 (22.4\%) & 46 (58.2\%) & $3(20 \%)$ & $2(16.7 \%)$ \\
\hline $5 \mathrm{~A}$ & $149(35.6 \%)$ & 15 (25.9\%) & $9(18.4 \%)$ & $29(36.7 \%)$ & $3(20 \%)$ & $2(16.7 \%)$ \\
\hline $5 \mathrm{~B}$ & $89(21.2 \%)$ & $6(10.3 \%)$ & $2(4.1 \%)$ & $17(21.5 \%)$ & 0 & 0 \\
\hline Total & $419(100 \%)$ & $58(100 \%)$ & 49 (100\%) & 79 (100\%) & 15 (100\%) & 12 (100\%) \\
\hline
\end{tabular}


$\left(\mathrm{p}=0.0001, \chi^{2}=31.57, \mathrm{df}=10\right)$. A higher proportion of children in the moderate and severe groups had slightly worse outcomes at $\leqslant 1$ year post-injury than the group as a whole. However, no significant differences in outcome were observed for children $\leqslant 1$ year post-injury compared with children $>1$ year post-injury.

KOSCHI scores were compared for children who, according to parental report, had or had not received follow up after hospital discharge. There were significant differences between outcome groups $\left(p=0.006, \chi^{2}=10.37, d f=2\right)$. In the moderate disability group $64 \%$ had no follow up, and in the good recovery group $76 \%$ had no follow up.

For the mild HI group $(\mathrm{n}=419)$, KOSCHI outcomes were analysed according to whether or not the child sustained a skull fracture. Moderate disability was observed for $50.8 \%$ (30) of the 59 children with skull fracture and $41.5 \%$ (147) of the 354 without (data were missing for 6 children). The difference was not significant $\left(\mathrm{p}=0.18, \chi^{2}=1.79, \mathrm{df}=1\right)$. Approximately $20 \%$ of both groups made a full recovery (5B).

KOSCHI outcomes were analysed according to Townsend deprivation scores $(\mathrm{n}=495)$ using the independent samples $t$ test. Children with good recovery (KOSCHI 5A/5B, $\mathrm{n}=252$ ), were compared with children with moderate/severe disability (KOSCHI 3A-4B, $\mathrm{n}=243$ ). A significant relationship was observed between social deprivation and outcomes $(\mathrm{p}=0.001, \mathrm{t}=-3.27,95 \% \mathrm{CI}:-1.4$ to -0.3$)$.

\section{DISCUSSION}

The postal survey revealed a large group of children with residual symptoms following $\mathrm{HI}$, even up to 6 years postinjury. According to their parents, 148 children had a changed personality following the HI. As a result of the HI, almost half the study group had moderate disability according to the KOSCHI. Of these, one third of the severe group and one quarter of the moderate group had overt problems requiring assistance or supervision. Severe disability was rare, and 270 children $(51 \%)$ had made a good recovery, yet two thirds of these had some residual symptoms. The profile of questionnaire responders was virtually identical to that of non-responders. Furthermore, half the responders had children with few or no residual problems, indicating that the sample is probably representative of the whole population of head injured children admitted to hospital in North Staffordshire.

The KOSCHI is a simple outcome scale, which proved relatively easy to score by a single experienced rater. However, differences between sub-categories would benefit from further clarification. Most of our respondents (99\%) were living with their parents in the community at the time of the survey, most were functionally independent, and few had physical problems. In this group, the classification of "moderate disability" was usually applied to children with learning, behavioural, or neurological sequelae affecting function. Children with severe behavioural problems or learning difficulties requiring supervision or help were placed in category 4A, even though the child was otherwise independent. Children with frequent temper tantrums, mood swings, aggressive behaviours, communication or concentration problems, and mild learning difficulties were placed in 4B. Half the study group had made a good recovery, but only $97(18.4 \%)$ made a full recovery with no discernible sequelae. The most usual reason for placing a child in category $5 \mathrm{~A}$ (good but not full recovery) was the presence of headaches not interfering with functioning.

The relatively high proportion $(43 \%)$ of children with mild HI but moderate disability was surprising. Furthermore, evidence of skull fracture was not associated with worse outcomes. The majority of children with mild HI had made a good functional recovery, but had difficulties that interfered with their daily lives, such as temper outbursts, mood swings, memory problems, and learning difficulties. The authors of the KOSCHI emphasise that relatively minor residual deficits are potentially more destructive to children than to adults, and the scale acknowledges this by identifying sequelae that may interfere with schoolwork and social functioning. ${ }^{19}$

The literature is inconclusive regarding the impact of mild HI on outcome, largely because of inconsistencies in the definition of "mild".24-27 Our "mild" group are at the more severe end of the spectrum of mild HI, as all had been admitted to hospital, which may help to explain the high proportion of those with moderate disability. However, further prospective research is required to address the important issue of residual disability after mild $\mathrm{HI}$ in greater depth, using clearly defined injury severity.

A relationship was observed between social deprivation and outcomes; children from deprived areas were significantly less likely to achieve a good recovery. Other investigators have observed an association between outcome and parental socioeconomic status and deprivation. ${ }^{13} 2829$

Cognitive and behavioural problems were frequently reported by our study group, even several years post-injury, a finding consistent with that of other investigators. ${ }^{17}{ }^{30-32}$ Although data on the frequency of symptoms were reliant upon parental report and thus subjective, it has been argued that parents are more likely to under-report than to exaggerate symptoms. ${ }^{17}$ In our study, the mild HI group experienced many symptoms "occasionally" as often as the moderate and severe groups; however, for most symptoms, children in the moderate and severe groups experienced them "frequently", far more often. We observed a significant linear trend across severity groups; increased injury severity was associated with increased symptom reporting.

The teachers of only 209 (39.8\%) children were aware of the HI. Given the persistent nature of cognitive and behavioural problems following a moderate or severe HI identified by other studies, this is of concern. ${ }^{11}{ }^{12}{ }^{31}$ Following their return to school after the HI, 96 children had been disciplined for problem behaviour, approximately 20\% of children in each severity group, and 27 children had been excluded from school. Recent research has found inadequate educational provision for children after head injury, largely due to inaccurate information, and inadequate communication and training. ${ }^{33}{ }^{34}$ We found that even when SEN were identified, according to parents they were only actually provided for in $65 \%$ of cases. The statutory framework for identification and provision of SEN has accepted limitations and the system is currently under review. ${ }^{35}$ The KOSCHI takes account of educational and behavioural difficulties, and may provide a means of identifying those children at risk of school underachievement, so that extra support can be arranged.

\section{CONCLUSIONS}

A significant proportion of children admitted with mild HI was found to have moderate disability at follow up. Given the large numbers of children presenting with mild HI, this represents a high prevalence of persistent problems. We were unable to identify a threshold of injury severity below which the risk of late morbidity could be discounted; however, children from deprived areas may have an increased risk of a poor outcome. It is recommended that further research be carried out to identify alternative risk factors. Although all children in the study had been admitted to hospital following the HI, only $30 \%$ of parents reported that their child had been offered a follow up appointment by the hospital. Furthermore, 161 children with moderate disability following HI received no follow up. A solution may be for clinicians to use a postal follow up to assess outcomes after hospital 
discharge, using a structured questionnaire incorporating the Kings' HI outpatient follow up checklist. KOSCHI outcome scores may then be used to identify those children who could benefit from follow up assessment; it may therefore be a way of using scarce NHS resources effectively.

\section{Authors' affiliations}

C A Hawley, Centre for Health Services Studies, University of Warwick, Coventry, UK

A B Ward, North Staffordshire Rehabilitation Centre, The Haywood, High Lane, Burslem, Stoke-on-Trent, Staffordshire ST6 7AG, UK A R Magnay, Paediatric Intensive Care Unit, City General Hospital, Newcastle Road, Stoke-on-Trent, Staffordshire ST4 6QG, UK J Long, North Staffordshire Rehabilitation Centre, The Haywood, High Lane, Burslem, Stoke-on-Trent, Staffordshire ST6 7AG, UK

Competing interests: none declared

\section{REFERENCES}

1 Kraus JF, Rock A, Hemyari P. Brain injuries among infants, children, adolescents, and young adults. Am J Dis Child 1990;144:684-91.

2 Guyer B, Ellers B. Childhood injuries in the United States. Am J Dis Child 1990; 144:649-52.

3 Snow JH, Hooper SR. Pediatric traumatic brain injury. California: Sage Publications, 1994.

4 Sharples PM. Head injury in children. In: Little RA, Ward Platt MP, eds. Injury in the young. Cambridge: Cambridge University Press, 1998:151-75.

5 House of Commons Select Committee on Health. Third report: head injury: rehabilitation. London: HM Stationery Office, 2001

6 Ewing-Cobbs L, Miner ME, Fletcher JM, et al. Intellectual, motor, and language sequelae following closed head injury in infants and preschoolers. J Pediatr Psychol 1989;14:531-7.

7 Klonoff $\mathrm{H}$, Clark C, Klonoff PS. Long-term outcome of head injuries: a 23 year follow up study of children with head injuries. J Neurol Neurosurg Psychiatry 1993;56:410-15.

8 Ewing-Cobbs L, Thompson NM, Miner ME, et al. Gunshot wounds to the brain in children and adolescents: age and neurobehavioural development. Neurosurgery 1994;35:225-33.

9 Parmelee DX. Neuropsychiatric sequelae of traumatic brain injury in children and adolescents. Psychiatr Med 1989;7:11-16.

10 Fletcher JM, Ewing-Cobbs L, Miner ME, et al. Behavioural changes after closed head injury in children. J Consult Clinical Psychol 1990;58:93-98.

11 Rivara JB, Fay GC, Jaffe KM, et al. Predictors of family functioning one year following traumatic brain injury in children. Arch Phys Med Rehabil 1992;73:899-910.

12 Rivara JB, Jaffe KM, Fay GC, et al. Family functioning and injury severity as predictors of child functioning one year following traumatic brain injury. Arch Phys Med Rehabil 1993;74:1947-55.

13 Rivara JB, Jaffe KM, Polissar NL, et al. Family functioning and children's academic performance and behaviour problems in the year following traumatic brain injury. Arch Phys Med Rehabil 1994;75:369-79.
14 Middleton JA. Practitioner review: psychological sequelae of head injury in children and adolescents. J Child Psychol Psychiatry 2001;42:165-80.

15 Cicerone KD, Smith LC, Ellmo W, et al. Neuropsychological rehabilitation of mild traumatic brain iniury. Brain Inj 1996;10:277-86.

16 Roberts MA, Manshadi FF, Bushnell DL, et al. Neurobehavioural dysfunction following mild traumatic brain injury in childhood: a case report with positive findings on positron emission tomography (PET). Brain Inj 1995;9:427-36.

17 Klonoff H, Clark C, Klonoff PS. Outcome of head injuries from childhood to adulthood: a twenty-three-year follow-up study. In: Broman SH, Michel ME, eds. Traumatic head injury in children. New York: Oxford University Press, 1995:219-34

18 Jennett B, Bond M. Assessment of outcome after severe brain damage. A practical scale. Lancet 1975:1:480-4.

19 Crouchman M, Rossiter L, Colaco T, et al. A practical outcome scale for paediatric head injury. Arch Dis Child 2001;84:120-4.

20 Teasdale G, Jennett B. Assessment of coma and impaired consciousness: a practical scale. Lancet 1974;2:81-3.

21 British Society of Rehabilitation Medicine. Rehabilitation after traumatic brain injury. A working party report of the British Society of Rehabilitation Medicine. London, 1998.

22 Townsend P, Phillimore P, Beattie A. Inequalities in health in the Northern region. Newcastle upon Tyne: Northern Regional Health Authority and University of Bristol, 1986.

23 Nash J, Appleton R, Rowland B, et al. Immediate medical and nursing needs. In: Appleton R, Baldwin T, eds. Management of brain-injured children. Oxford: Oxford University Press, 1998:43-70.

24 Homer CJ, Kleinman L. American Academy of Pediatrics: Technical report: Minor head injury in children. Pediatrics 1999;104:1-7.

25 Tellier A, Della Mavla LC, Cwinn A, et al. Mild head injury: a misnomer. Brain Ini 1999;13:463-75.

26 McKinlay A, Dalrymple-Alford JC, Horwood $\amalg$, et al. Long term psychosocial outcomes after mild head injury in early childhood. I Neurol Neurosurg Psychiatry 2002;73:281-8.

27 Kay A, Teasdale G. Head injury in the United Kingdom. World J Surg $2001 ; 25: 1210-20$

28 Chadwick O, Rutter M, Brown G, et al. Intellectual performance and reading skills after localised head injury in childhood. J Child Psychol Psychiatry 1981;22:117-39.

29 Max JE, Roberts MA, Koele SL, et al. Cognitive outcome in children and adolescents following severe traumatic brain injury: Influence of psychosocial, psychiatric and injury-related variables. $J$ Int Neuropsychol Soc 1999;5:58-68.

30 Chadwick O, Rutter M, Brown G, et al. A prospective study of children with head injuries: II. Cognitive sequelae. Psychol Med 1981;11:49-61.

31 Scott-Jupp R, Marlow N, Seddon N, et al. Rehabilitation and outcome after severe head injury. Arch Dis Childhood 1992;67:222-6.

32 Donders J, Ballard E. Psychological adjustment characteristics of children before and after moderate to severe traumatic brain injury. J Head Trauma Rehabil 1996;11:67-73.

33 Jones A, Johnson D. A study of the educational provision for head-injured children. Br J Spec Educ 1994;21:113-17.

34 Johnson DA, Munro S, Pentland B, et al. Educational needs after head injury in children. Report to the Scottish Office. Edinburgh: Astley Ainslie Hospital, 1998

35 Audit Commission. Statutory assessment and statements of SEN: in need of review? London: The Audit Commission, 2002. 